\title{
Projetando com Blocos de Montar Digitais: Possibilidades e Limitações do Jogo LEGO Digital Designer
}

Designing with Digital Building Blocks: Possibilities and Limitations of the LEGO Digital

Designer Game

\author{
Frederico Braida \\ Universidade Federal de Juiz de Fora, Brasil \\ frederico.braida@ufjf.edu.br \\ Janaina Mendes de Castro \\ Universidade Federal de Juiz de Fora, Brasil \\ janaina.mendes@arquitetura.ufjf.br \\ Letícia Bedendo Campanha Pires \\ Universidade Federal de Juiz de Fora, Brasil \\ leticia.pires@arquitetura.ufjf.br
}

\author{
Luiz Antônio Rozendo Pereira \\ Universidade Federal de Juiz de Fora, Brasil \\ antonio.rozendo@arquitetura.ufjf.br \\ Marcela Martins Cavalari Cardoso \\ Universidade Federal de Juiz de Fora, Brasil \\ marcela.cavalari@arquitetura.ufjf.br
}

\begin{abstract}
This article proposes a reflection on the possibilities of using building blocks games as educational tool applied to the universe of Architecture and Urbanism design, from literature search and empirical data gathered in a workshop coordinated by the Research Group of Languages and Expressions in Architecture, Urbanism and Design - LEAUD (Brasil). The goal is to highlight the possibilities and limitations of using projetual world of building blocks as an academic material for Architecture and Urbanism, especially after the experience with LEGO Digital Designer software.
\end{abstract}

Keywords: Design methodology; Building blocks; LEGO; Digital game; Design worlds.

\section{Introdução}

Os blocos de montar, entendidos como jogos, foram sistematicamente utilizados por Vygotsky e Piaget no âmbito educacional, além de serem amplamente explorados pela pedagogia construtivista de Montessori. Também no campo específico da Arquitetura e do Urbanismo, os blocos de montar, aqui abordados como um "mundo projetual" (Mitchell, 2008), têm sido utilizados por projetistas, seja no meio acadêmico ou profissional. Por exemplo, têm-se as LEGO Towers e LEGO House projetadas pelo escritório de arquitetura BIG (BjarkelngelsGroup).

Nos dias de hoje, a utilização dos blocos de montar expandiuse para 0 meio virtual/digital. Agora, somam-se às características tradicionais, as possibilidades interativas e de construção coletiva. Por exemplo, o jogo virtual Minecraft explora o mundo projetual dos blocos em videogames (Braida et al., 2015).

Segundo Mattar (2009 apud Carniello, Rodrigues \& Moraes, 2010), o aprendizado baseado em jogos digitais está fundamentado em duas premissas:

[...] os aprendizes mudaram em diversos pontos essenciais e são de uma geração que experimentou profundamente, enquanto crescia, uma forma radicalmente nova de jogar - computadores e videogames. (p.12).
Algumas pesquisas evidenciam que, com o decorrer dos anos, vem aumentando tanto o acesso aos jogos como o tempo dispendido no ato de jogar. Por exemplo, segundo o estudo divulgado pelo instituto de pesquisas Ipsos,em 2012, o número de brasileiros acima de 10 anos que possuíam consoles de games aumentou de $27 \%$ para $30 \%$ (em um período de cinco anos)(Brasileiros..., [s.d.]).Com relação ao tempo gasto com jogos, o brasileiro, que costumava jogar durante três horas e sete minutos por semana (em 2008), passou a investir quatro horas e treze minutos semanais em jogos (no final de 2012).

A pesquisa também demonstrou que as faixas etárias mais elevadas representavam uma quantia significativa para o mercado de consoles, o que demonstra a importância dos jogos na atualidade, assim como sua potencialidade quanto ferramenta educativa (de ensino e aprendizagem).

Diante desse cenário, neste artigo, propõe-se uma reflexão conceitual/crítica sobre as possibilidades do emprego dos videogames que exploram o mundo dos blocos de montar. Objetiva-se, portanto, evidenciar as possibilidades e as limitações do uso do mundo projetual dos blocos de montar digitais como material didático para Arquitetura e Urbanismo, sobretudo a partir da experiência levada a cabo em um Workshop com a utilização do jogo LEGO Digital Designer. 


\section{O Jogo: de Elemento Social a Ferramenta Educativa}

A presença dos jogos na vida do homem é antiga e sua função na sociedade foi se modificando com o decorrer do tempo. Huizinga (2007), ao refletir sobre a relação ócio versus trabalho,afirma que os jogos já estiveram mais presentes no cotidiano humano, promovendo a socialização. Muitas vezes, eles estavam associados aos cultos e rituais, compartilhando características como: "ordem, tensão, mudança, movimento, solenidade e entusiasmo." (Volpato, 2002 , p. 218). Além disso, tanto os jogos como os ritos apresentavam a mímesis e, ao mesmo tempo, a capacidade de transportar os indivíduos para outra dimensão, aonde as regras da realidade eram extrapoladas.

No século XVIII, com o desenvolvimento do capitalismo e a crescente racionalização da sociedade, principalmente ocidental, os brinquedos passaram a ser produzidos com fins lucrativos e se tornaram mais específicos. "O que antes era motivo de profundas relações familiares, com valores e sentidos culturais muito significativos, torna-se objeto destinado a um público-alvo, com um fim em si mesmo." (Volpato, 2002, p. 220).

Os brinquedos produzidos pela indústria de massa, assim como os fabricados para o ambiente escolar, tendem a inibir a capacidade imaginativa das crianças. Em ambos, a racionalização é enfatizada. Alexandre e Sabbatini (2013) também identificaram que muitos jogos perdem suas potencialidades quando voltados para a educação, desfazendo-se de suas características lúdicas ou, ainda, classificando-se mais como atividades lúdicas do que como jogos propriamente ditos.

Segundo Volpato (2002), a Teoria Crítica defende o estímulo da imaginação aliado a um aprofundamento do entendimento desse processo, permitindo com que as crianças internalizem conceitos a partir do brincar. Podemos compreender, de acordo com a definição de Huizinga (2007, p.33), que

[...] o jogo é uma atividade ou ocupação voluntária, exercida dentro de certos e determinados limites de tempo e espaço, segundo regras livremente consentidas, mas absolutamente obrigatórias, dotado de um fim em si mesmo, acompanhado de um sentimento de tensão e de alegria e de uma consciência de ser diferente da "vida cotidiana".

Apesar de vários estudos e teóricos reforçarem a importância de jogos e atividades lúdicas no processo de aprendizagem, a inserção desses na educação ainda enfrenta dificuldades. Rocha (2009) realizou uma pesquisa em 2006, para observar os impactos da implementação do Ensino Fundamental de nove anos no Brasil. A autora identificou que a falta de verbas, de preparo dos professores e de credibilidade dos pais dos alunos em aceitar as atividades lúdicas como ferramentas de ensino atrapalharam na consolidação destes como metodologia educativa.

No entanto, deve-se ponderar que não é somente no Ensino Infantil ou no Ensino Básico que os jogos podem ser extremamente úteis. A utilização de jogos como estratégia pedagógica também pode acompanhar os processos de formação de adultos, seja nas universidades ou, até mesmo, no meio profissional. Vale ressaltar que a "gameficação" tornou-se uma prática social contemporânea, alastrada por quase todos os campos da atuação humana (Burke, 2015; Alves, 2015).

Dentre as diversas modalidades de jogos, destacam-se, neste artigo, os blocos de montar, os quais apresentam um grande potencial para o ensino de projeto de Arquitetura e Urbanismo, devido às seguintes características: despertar a criatividade, a partir de abstrações; possibilitar composições volumétricas (modulares); submeter-se a regras definidas pelos jogadores, por exemplo, valendo-se da Gramática da Forma(Stiny\&Gips, 1972).

\section{O Ensino com Blocos de Montar}

O educador alemão Friedrich Wilhelm August Fröbel desenvolveu, entre 1830 e 1852, o primeiro sistema de Jardim de Infância baseado em jogos e atividades lúdicas. $O$ brincar, para ele, era uma experiência que permitia às crianças criar significados, compreender o funcionamento de objetos e ações, e entender seus papéis de agentes criativos no mundo (Ostrower, 2008).

Os blocos de montar de Fröebel, mais conhecidos por Fröebel Gifts, podem ser classificados em três linhas, conforme encontrados no site FroebelGifts <http://froebelgifts.com/>. Formas de vida: quando utilizados pelas crianças para imitar a vida real, na qual a combinação dos blocos mimetiza torres e pontes, por exemplo. Ao brincar, elas fazem associações e contam histórias, assimilando a realidade. Os jogos também são formas de conhecimento, estimulando o raciocínio matemático e racional, a partir da compreensão das três dimensões espaciais por meio das peças e servindo para soma, subtração, multiplicação etc. E, por fim, em formas de beleza, as crianças são estimuladas a rearranjar as formas, criando novas composições e desenvolvendo noções de proporção, simetria e ritmo. Nas duas linhas criativas, Fröebel ressalta a necessidade de liberdade para as crianças experimentarem.

Na Figura 1, tem-se os blocos de montar que vão do Gift 3 ao 7. Os posteriores são criações de seguidores de Fröebel.

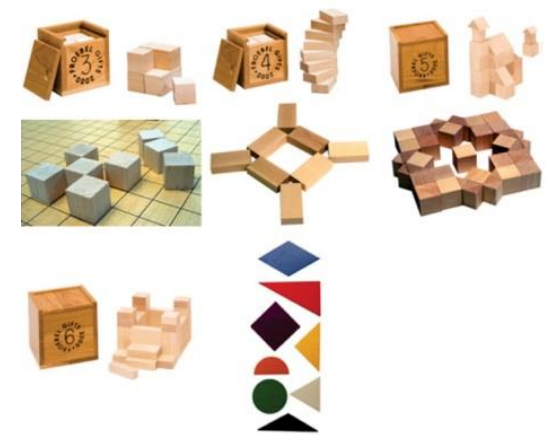

Figura 1: FröebelGifts. Disponível em: <http://froebelgifts.com/gift6.htm>. Acesso em: 12 jun. 2016.Montagem dos autores. 
O jogo 6 (Gift6) de Fröebel traz mais variações e proporções de peças que os anteriores, além de remeter à arquitetura real mais diretamente, por meio de componentes como coberturas e colunas. $\mathrm{O}$ arquiteto Frank Lloyd Wright ganhou esses blocos quando criança; e ele mesmo falava abertamente sobre a influência que eles tiveram na sua compreensão de projeto. Parte desse relato encontra-se publicado no livro A Testament, de 1957:

Eu sentei em cima da pequena mesa do jardim de infância e brinquei com o cubo, a esfera e o triângulo. Logo me tornei suscetível ao padrão construtivo evoluindo em tudo o que eu via. Eu aprendi a ver dessa maneira e, quando consegui, eu não me preocupei em desenhar incidentes casuais da natureza. Eu queria projetar. (The Froebel..., 1985, tradução nossa).

Muitas representações das construções de Wright (como, por exemplo, a UnityTemple, na Figura 2) podem ser feitas com os blocos de Fröebel, as quais demonstram as correlações entre os dois.

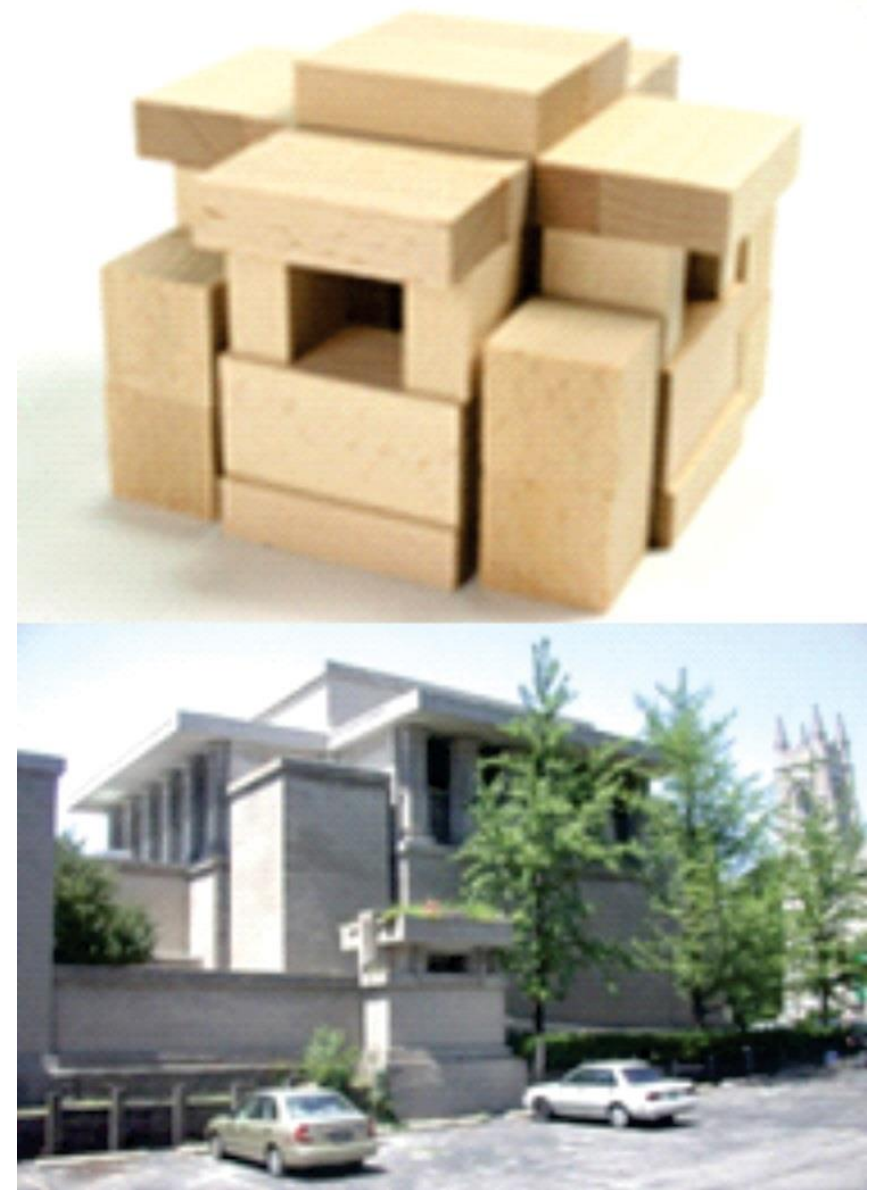

Figura 2:UnityTemple de Frank Lloyd Wright - versão blocos de Fröebel. Disponível em: <http://q-bamaze.typepad.com/content/2007/07/did-a-childhood.html>. Acesso em: 12 jun. 2016. Montagem dos autores.

\section{O Uso e a Propagação dos Blocos de Montar LEGO: da Madeira ao Plástico}

A empresa LEGO foi criada em 1932, pelo dinamarquês OleKiek Christiansen. Inicialmente, ela fabricava brinquedos de madeira (Vieira, Alexandre\& Garcia, 2015), porém não obteve sucesso até 1958. Nesse período, os blocos plásticos ganharam um sistema de conexão, superando os blocos de Fröebel.

Nos anos iniciais da década de 1960 , os blocos da LEGO passaram por uma revisão do seu design. O processo de revisão proposto por Godfreg Kirk Christiansen, filho do fundador da empresa, estabeleceu como meta a criação de componentes que dessem ao LEGO uma nova dimensão. Então, foram criados cinco novos elementos que pudessem combinar com os blocos já existentes. As novas peças, com um terço da altura dos blocos pré-existentes, possibilitaram a construção de modelos mais complexos.

Logo, esses blocos se tornaram mais uma fonte de inspiração arquitetônica. As possíveis relações entre os blocos de montar e a concepção arquitetônica já fazia parte do discurso da empresa, tanto que, em 1962, a LEGO lançou os "modelos em escala", baseados em obras de arquitetura e engenharia.

Destaca-se que a noção de escala não está presente apenas nos blocos; ela também se manifesta na representação das figuras humanas, as chamadas mini-figures, ou bonequinhos de LEGO, sem cabelo ou chapéu, os quais não ultrapassam a altura de quatro blocos simples empilhados (lógica que permanece no Lego Digital Designer). De acordo com Cavazzini (2014), essa proporção se faz necessária para que os bonecos caibam na maioria dos modelos, entre eles veículos, naves e estruturas.

Nos dias de hoje, a empresa é de propriedade de Kjeld Kirk Kristiansen, neto do fundador, e continua atraindo a atenção de estudantes e profissionais de arquitetura e urbanismo (Fontenelle, 2012). Os produtos da linha LEGO Architecture são voltados, prioritariamente, para esse público. Dentre os produtos, destaca-se o LEGO Architecture Studio, que se trata de uma caixa com 1210 peças brancas e transparentes, destinadas a uma ampla diversidade de composições formais.

No Brasil, os blocos LEGO vêm sendo explorados por profissionais, como 0 arquiteto Demetre Anastassakis. Demetre, de naturalidade grega, que tem grande expressividade em projetos de habitações sociais, nos quais utiliza blocos LEGO para auxiliar na concepção.

De acordo com Anastassakis (2016), no fim dos anos de 1990, ele se juntou a outros arquitetos e estudantes de diversas áreas (arquitetura, engenharia, sociólogos etc.) para formar o grupo CoOperaAtiva, a fim de disputar um concurso de habitação popular em São Paulo. Na época, eles já utilizavam o LEGO para brincar com os filhos, portanto, também se valeram dos blocos para a exploração do pensamento projetual. 
Para esse grupo, o módulo de projeto seria o quarto mais comum na casa brasileira - o de $3 \mathrm{~m} \times 3 \mathrm{~m}$ em planta. Então, verificaram que o bloco básico do LEGO de quatro pinos representava o cômodo em escala 1:200. Embora a altura ficasse com uma diferença em escala, não chegava a comprometer a concepção do projeto.

Esse entendimento, assim como a utilização dos blocos de LEGO, facilitou na elaboração de projetos diferentes, porém com a mesma área e mesmo custo. A partir da análise combinatória espacial dos cômodos "componentes" variavamse os espaços, "com varandinhas, terraços, balanços, e podendo exercitar à vontade, geminação, justaposição e sobreposição das unidades assim obtidas" (Anastassakis, 2016). Nota-se, portanto, o uso, ainda que intuitivo, de uma Gramática da Forma.

Ainda segundo o arquiteto, o LEGO é necessário, mas não suficiente. É um método que auxilia muito na elaboração de espaços não repetitivos, a partir de tentativas e erros e análises combinatórias. Porém, outras ferramentas são utilizadas para a definição dos espaços internos e registro mais técnico. Em casos mais complexos, o arquiteto utiliza, ainda, o SketchUp para verificar as volumetrias decorrentes.

Assim, percebe-se que os blocos de montar LEGO, embora apresentem limitações específicas, tais como qualquer outro mundo projetual, possibilitam a exploração arquitetônica e urbanística, de forma lúdica e intuitiva (experimental).

\section{LEGO Digital Designer: do "Real" ao "Virtual"}

O LEGO Digital Designer (LDD), versão 4.3.9, é um programa elaborado pela mesma companhia dos blocos físicos LEGO. O programa viabiliza a montagem decomposições (construções), tais como aquelas possíveis com os blocos de plástico, porém no mundo virtual.

A interface do software (Figura 3) é simples e intuitiva. O plano de montagem é quadriculado e se apresenta em uma perspectiva isométrica. Há a possibilidade de zoom, mudança de órbita e rotação do plano. A base se expande simultaneamente ao aumento da criação.

Com relação aos menus, à esquerda da janela tem-se uma coluna com as opções de peças disponíveis em várias cores, incluindo as com transparência. $\mathrm{Na}$ parte superior central,tem-se uma barra de ferramentas que auxilia na manipulação dos blocos.é importante destacar que, apesar de se moverem em todos os eixos, o ângulo de rotação das peças é sempre ortogonal.

Conforme o usuário começa a montar os blocos, a opção Buildingguidemodese torna disponível. Ela mostra o passo a passo do projeto, sendo um guia de montagens para outras pessoas, caso o modelo seja compartilhado com a LEGO, opção também presente no jogo.

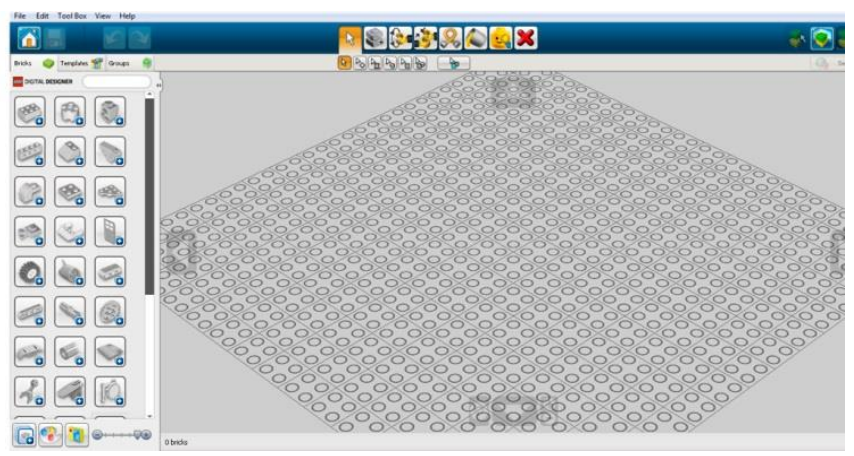

Figura 3: Interface do LEGO Digital Designer. Fonte: Acervo dos autores, 2016.

Durante seis anos, a empresa LEGO possibilitou aos seus consumidores adquirirem os modelos que construíam virtualmente com o software. Para isso, eles enviavam os modelos construídos e recebiam as peças em uma caixa LEGO própria. Porém, o serviço parou de ser prestado em 2012. De acordo com a empresa, a demanda por essa oferta cresceu tanto que poderia comprometer o padrão de qualidade e, portanto, a solução foi encerrar o serviço temporariamente.

Em contrapartida, surgiu a opção dos usuários enviarem os seus modelos para uma galeria pública presente no site do software. Na galeria há possibilidades de interação, tais como curtir as criações de outras pessoas, assim como fazer o download dos modelos para abrir no LEGO Digital Designer.

Além do plano de montagem, há a opção Viewmode de visualização. Nela, a criação aparece sobre um plano de fundo bidimensional, porém com visualização em $360^{\circ}$. As mesmas opções de movimento de plano presentes na interface de construção permanecem nesse modo, sendo possível girar em torno do modelo criado e dar zoom, porém não é possível mexer nas peças. São oferecidos quatro planos de fundo diferentes. Além disso, há a opção Screenshot eExplode themodel (decomposição do modelo).

Embora a interface seja de grande utilidade para projetos modulares de arquitetura e urbanismo, ela apresenta uma limitação importante: a falta de contextualização da construção perante o entorno e a passagem do tempo limitação não encontrada quando se utiliza o mundo projetual dos blocos de montar do Minecraft (Braida et al., 2015).

No intuito de aumentar sua distribuição, em 2014, a LEGO se uniu ao Google e lançaram conjuntamente o "Build with Chrome" (Quirk, 2014). Nele, é possível escolher um sítio para a inserção do elemento criado, devido à integração do jogo com o Google Maps. Dessa forma, o usuário encontra sua criação limitada ao local escolhido no mapa e a paisagem permanece em duas dimensões. Assim como no Google Earth, é possível encontrar algumas obras já consolidadas de certas paisagens, como é o caso do Cristo Redentor no Rio de Janeiro, do MASP de Lina Bo Bardi em São Paulo e daTorre Eiffel em Paris, no formato LEGO.

Quando comparado ao LEGO Digital Designer, o "Build with Chrome" apresenta menos opções de peças e de cores. $O$ 
LDD ainda conta com um espaço ilimitado para a construção de modelos e também com ilimitada quantidade de peças, além de todas estarem disponíveis desde um primeiro momento, não havendo assim a necessidade de passar de nível (level) para obter novas peças.

Indo além das possibilidades oferecidas pela empresa LEGO, o estúdio londrino Gravity vem testando a geração de modelos virtuais em tempo real por meio de sensores giroscópicos e mapas de localização acoplados às peças LEGO (Figura 4). Nomeado de "LEGO X", o projeto utiliza algoritmo para suavizar as arestas, buscando otimizar o processo de modelagem e impressão 3D (Rosenfield, 2015).

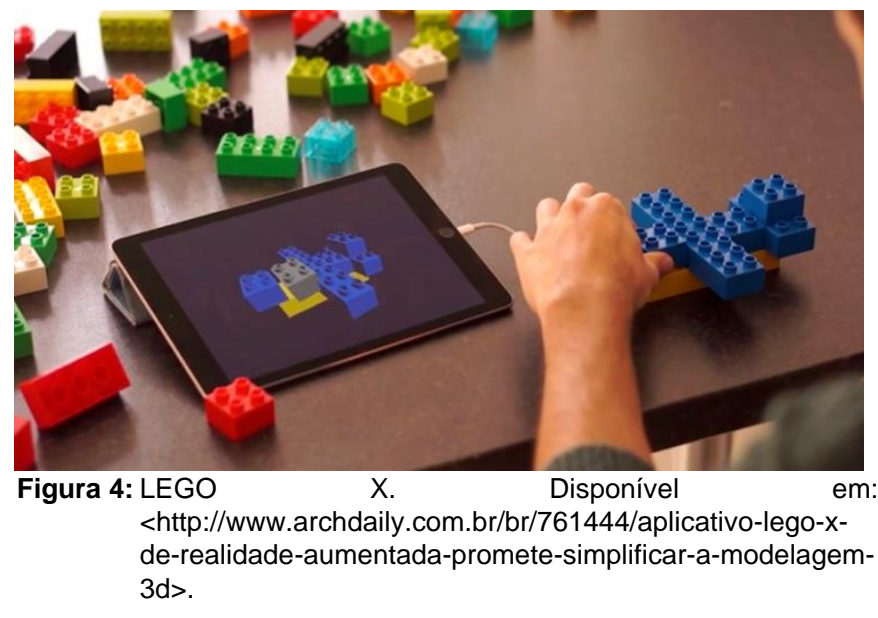

\section{Metodologia e Materiais: o Workshop "Projetando com o LEGO Digital Designer (LDD)"}

Conforme já explicitado, metodologicamente, este artigo é resultado de uma pesquisa tanto teórica quanto empírica, uma vez que se fundamenta em uma revisão bibliográfica e em uma experiência didática realizada em um Workshop (estudo de caso), em maio de 2016, coordenado pelos pesquisadores do Grupo de Pesquisa LEUAD/UFJF, levado a cabo no Laboratório de Expressão e Representação Digital da Faculdade de Arquitetura e Urbanismo da Universidade Federal de Juiz de Fora (FAU/UFJF).

O workshop foi coordenado pelo professor/pesquisador Dr. Frederico Braida, pelos bolsistas de iniciação científica, Janaina Castro e Marcela Cardoso, e de treinamento profissional, Letícia Pires e Luiz Antônio Pereira, vinculados a projetos de pesquisa financiados, respectivamente, pela Fundação de Amparo à Pesquisa do Estado de Minas Gerais (FAPEMIG) e pela Pró-Reitoria de Graduação (PROGRAD) da UFJF.

Ao todo, participaram 34 (trinta e quatro) estudantes; em sua maioria, do terceiro período da FAU/UFJF.O workshop foi ministrado em duas sessões e se desenvolveu durante os horários da disciplina de Modelagem Digital e Prototipagem, que é dividida em duas turmas (18 alunos pela manhã e 16, pela tarde), com duração de 3 horas/aula cada turno.
A escolha da turma deveu-se ao fato de os alunos ainda estarem no Ciclo Básico do Curso, mas já terem um contato prévio com softwares como Sketchup, AutoCad, Revit, Rhinoceros, Corel e Photoshop. Dessa forma, os alunos já teriam um repertório crítico para lidar com um projeto auxiliado por um software mais lúdico (um jogo digital), compreendendo suas limitações, mas explorando suas potencialidades.

Durante o workshop, intitulado "Projetando com o LEGO Digital Designer (LDD)", os alunos tiveram que conceber um memorial. Para tanto, inicialmente, foi feita uma apresentação acerca da interface do programa e do tema proposto memorial da saudade -, o que possibilitou uma exploração formal pouco restritiva, permitindo avaliações mais focadas no processo projetual com um jogo digital do que na dificuldade da solução programática e funcional.

Ressalta-se que o workshop se mostrou um lugar propício para a abordagem dos conteúdos da Gramática da Forma, uma vez que os alunos tiveram contato anterior com esse tema através de um seminário realizado para a disciplina de Modelagem Digital e Prototipagem. Dessa forma, durante a apresentação inicial do workshop, a Gramática da Forma foi brevemente revisada com os alunos, assim como as regras principais que ela oferece e que podem ser aplicadas aos blocos de montar, como translação, rotação, adição, subtração, substituição etc.

Dentre os exemplos de memorial apresentados aos estudantes, estava uma construção retirada da galeria pública do site do LDD. Trata-se de um modelo do Jefferson Memorial gerado no jogo e compartilhado na rede pelo usuário identificado por Nevermore60. A escolha desse exemplo baseou-se na necessidade de demonstrar as possibilidades e limitações formais, como a dificuldade de se gerar formas circulares ainda que existam algumas peças curvilíneas. Na Figura 5, pode-se perceber que o usuário pretendeu fazer uma curva com as "peças-pilares", porém ela não é completa, apresentando-se segmentada.

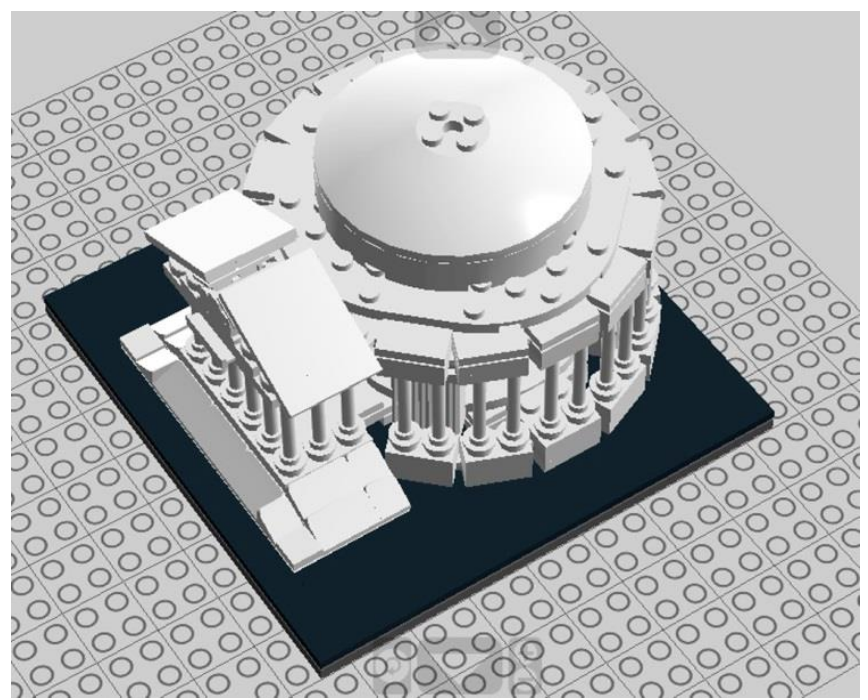

Figura 5:Jefferson Memorial, por Nevermore60. Fonte: Acervo dos autores. 
Foi solicitado aos participantes que trabalhassem dentro da gramática formal oferecida pelo jogo, ou seja, as regras formais desse mundo projetual deveriam ser estritamente respeitadas. O projeto foi desenvolvido em 1h30min. Os alunos poderiam trabalhar em duplas ou individualmente, bem como utilizarem ou não papel para desenhos de concepção.

Durante a realização da atividade, os participantes foram estimulados a compartilharem suas impressões da experiência do Workshop, informações que complementaram as respostas dos questionários e a solução formal obtida através do software. Ao fim, os estudantes apresentaram seus projetos para toda a turma.

\section{Discussões e Resultados}

A partir do diálogo desenvolvido durante o Workshop e das respostas coletadas em um questionário aplicado aos participantes, pode-se perceber que todos os alunos já possuíam algum contato prévio com jogos de blocos de montar físicos, sendo os mais citados o LEGO e o Brincando de Engenheiro. Um aluno disse ter usado os blocos de Fröebel e, outro, o material dourado (que foi interpretado como um jogo pelo aluno). Das opções de blocos de montar digitais, apenas uma participante já havia utilizado o LDD, sendo que o Minecraft também foi citado. Porém, poucos haviam explorado tanto esses jogos físicos quanto os digitais para a concepção projetual em arquitetura e urbanismo.

O período curto de tempo para projetar e a falta de contato prévio com o LDD pode ter sido a causa de algumas das limitações apontadas pelos participantes. Isso foi identificado a partir do questionamento: "Você prefere blocos de montar físicos ou digitais? Justifique a sua escolha". Dentre algumas das respostas para a opção "físicos" apareceram justificativas como "Certa dificuldade em me acostumar com o jogo", "Não usei" e "Não tenho muito contato com os blocos de montar digitais". Em outro trecho do questionário, um dos alunos afirma que "com mais tempo para experienciar o programa, seria possível realizar projetos bastante interessantes e mais completos.".

O grande número de peças disponíveis foi identificado por alguns como uma desvantagem pela dificuldade em encontrar as que desejavam ou de compreender a que fim algumas delas poderiam servir. Porém, a maioria apontou a oferta de peças como um aspecto positivo, como "uma alternativa aos blocos físicos para quem não tem acesso a tal material".

A gama de cores foi explorada para representar diferentes materiais. Observam-se, em diversos memoriais, peças transparentes representando vidro, o verde sugerindo grama e o azul como água. No geral, o colorido utilizado no projeto virtual era o pretendido na materialização do memorial, caso fosse construído na realidade.

Pode-se observar que a plataforma em que ocorre a montagem dos blocos apresenta-se, supostamente, como neutra, embora seja uma base plana com marcações de um grid formado pelos pinos do bloco de encaixe. Por não estimular o usuário a pensar em questões de contexto- temporal (como ocorre no Minecraft), como iluminação e intempéries, alguns projetos ficaram descontextualizados; mas há aqueles que buscaram modelar (representar) um entorno, de tal forma a dar mais sentido para seu próprio projeto.

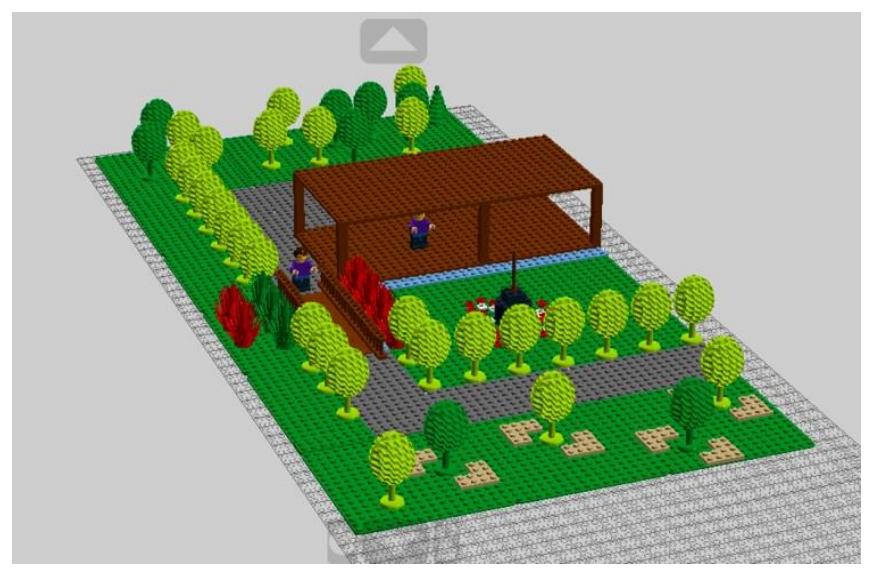

Figura 6:Memorial em que o entorno recebeu atenção especial, apresentando uma proposta paisagística. Fonte: acervo dos autores.

Vale destacar que a falta de entorno compromete noções de escala, proporção e medida. Apesar de existir a possibilidade de montar um boneco LEGO como referência de escala humana, nem todos os alunos se aproveitaram disso. Houve casos em que foi estabelecida uma medida para a altura das peças ao modelar, mas, mesmo assim, ocorreram falhas, como na Figura 7: os blocos foram pensados com uma altura de 3 metros, porém as peças utilizadas como bancos saíram da escala pretendida.

Um fato que se destacou foi o grande número de projetos com um vazio no local das aberturas. Não houve a preocupação em se colocar um material que representasse porta ou janela, por exemplo. Mesmo com o software oferecendo peças desses elementos, elas não foram utilizadas. Assim, verifica-se que os alunos produziram estudos mais volumétricos e não modelos de apresentação do projeto final, onde buscaram representar mais as relações entre cheios e vazios do que 0 detalhamento dos acabamentos.

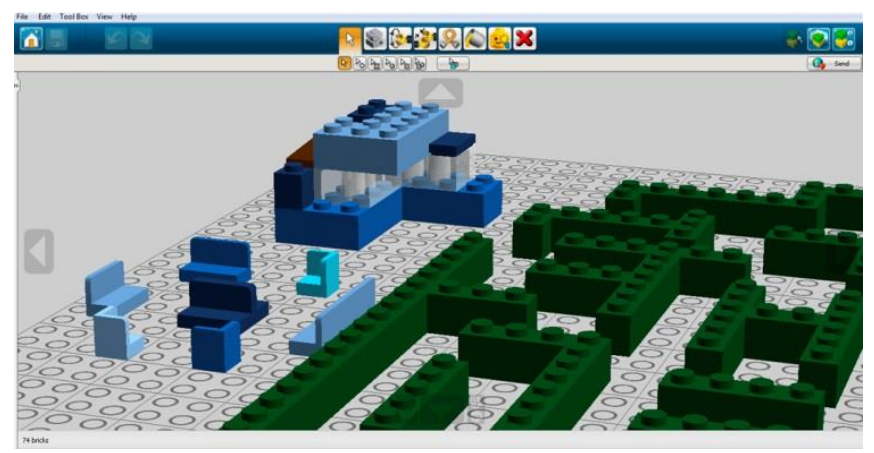

Figura 7:Exemplo de memorial feito no Workshop com problemas de escala entre os objetos. Fonte: acervo dos autores.

Quando questionados se o LDD também seria uma ferramenta de apresentação, alguns estudantes disseram 
preferir softwares que geram imagens renderizadas, mais próximas da apresentação real, justificando ser esta uma preferência dos clientes. Ainda assim, alguns cogitaram que é uma opção para trabalhos mais lúdicos.

Uma das potencialidades identificadas durante o Workshop foi a utilização do jogo na fase de estudo volumétrico e em concepções modulares, com as cores podendo auxiliar na setorização. O caráter lúdico do processo também foi percebido em algumas falas, por exemplo: "Uma forma diferente de brincar e projetar [...]" e "Foi uma experiência nova e divertida [...]".

Mesmo com a orientação de pensar dentro das possibilidades formais do LEGO, houve casos em que o participante não conseguiu obter o resultado esperado por desejar mais curvas ou, ainda, mover a peça em uma angulação diferente da ortogonal. Mas, a grande maioria conseguiu realizar o que desejava, orientando a concepção de acordo com o entendimento da ferramenta e da sua gramática formal. Observa-se que essa questão passa, também, pelo amadurecimento do projetista em saber compreender as limitações do mundo projetual com o qual está trabalhando e explorá-lo criativamente.

Quando comparado o LEGO físico com o LDD, o físico surge, em um primeiro contato, como opção mais fácil de assimilação e manipulação dos encaixes, por causa de sua materialidade. Uma alternativa que responde de forma interessante à essa questão é o projeto LEGO X, já citado, no qual a partir da utilização dos blocos de LEGO físicos se gera modelos virtuais. Sendo mais uma opção a ser explorada, em que as potencialidades dos dois ambientes podem convergir.

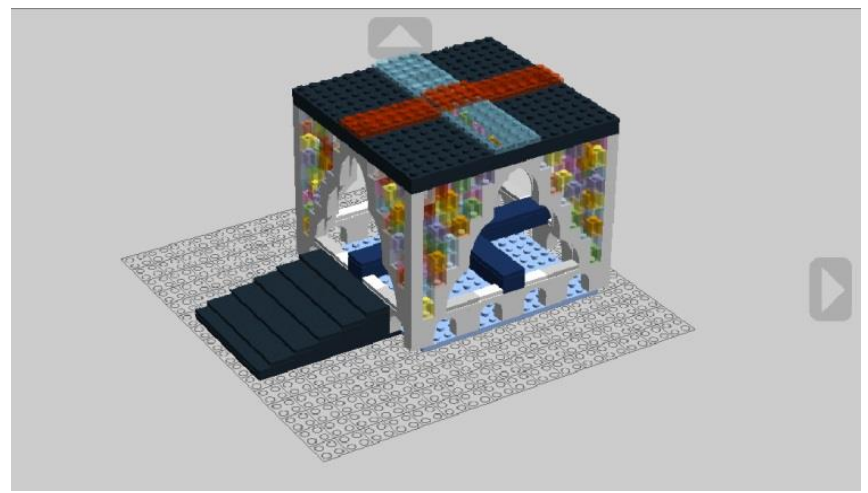

Figura 8:Exemplo de memorial que conseguiu desenvolver formas curvas a partir do vocabulário disponível. Fonte: acervo dos autores.

\section{Conclusões}

A interação entre elementos reais e virtuais é cada vez mais possível, sendo aprimorada para entretenimento, estudo e trabalho. A tecnologia possibilita que o usuário desenvolva estratégias, construa hipóteses e resolva problemas simulando o real.

Assim como outros softwares, o Lego Digital Designer possibilita oportunidades de experiências e visualização da forma no processo de criação. Quando se trata de arquitetura residencial modular, o jogo proporciona soluções formaiscriativas, podendo auxiliar na visualização da setorização dos ambientes através da utilização de diferentes cores.

A quantidade de peças disponíveis é outro aspecto positivo. Sendo uma opção lúdica no ensino de projeto arquitetônico de forma gratuita, demandando apenas um computador (não sofisticado). Dessa forma, os alunos podem gerar diversos modelos em uma única plataforma, compará-los e, inclusive, avaliar o desenvolvimento da proposta arquitetônica. Além de poder compartilhar o arquivo com outro estudante, que poderá editá-lo. O que, em um trabalho que se estenda a mais de um dia, não se torna tão viável com os blocos físicos, pois demanda o cuidado em manter a estrutura montada.

Ainda que o software apresente algumas limitações, tanto nos aspectos formais quanto na falta de um entorno, ele se torna interessante na geração de estudos volumétricos, assim como na solução de problemas diante de um vocabulário formal limitado, que desafia o estudante a testar diversas composições, estimulando, assim, a criatividade. Sendo uma ferramenta interessante para turmas iniciantes do curso de Arquitetura e Urbanismo, uma vez que pode servir de ponte intermediária entre uma forma mais lúdica e livre de se pensar a arquitetura para um pensamento projetual posterior que contará com condicionantes tipológicas, topográficas, climáticas, entre outros desafios.

Além disso, o jogo pode ser utilizado como ferramenta de aprendizagem tangencial (Alexandre \&Sabbatini, 2013), servindo para despertar o interesse dos alunos, através de um diálogo guiado pelo professor, para questões que vão além do jogo, como as que surgiram durante a apresentação das propostas elaboradas no Workshop, envolvendo a importância da escala e da contextualização do projeto. Sendo interessante também a comparação dele com outros softwares mais comuns no meio, como o SketchUp, no qual ocorre também a falta do entorno e demanda mais domínio das funções para uma manipulação mais efetiva.

Acredita-se que experiências como a que está relatada neste artigo são interessantes para despertar alunos e professores para a busca de ferramentas, muitas vezes, desconhecidas por eles. A partir desses resultados, já se torna possível uma comparação mais profunda entre jogos de blocos de montar diferentes, como o Minecraft, além de se pensar em quais atividades um jogo se torna mais efetivo do que o outro.

\section{Agradecimentos}

Agradecemos à Fundação de Amparo à Pesquisa do Estado de Minas Gerais (FAPEMIG) que tem financiado a pesquisa (Termos de outorga TEC - PPM-00766-15 e TEC - APQ01041-14), cuja parte dos resultados está relatada neste artigo. Agradecemos também à Universidade Federal de Juiz de Fora, em especial à PROGRAD e à FAU.

\section{Referências}

Alexandre, L. B., Garcia, L. S. B. \& Vieira, S. M. F. (2015).Lego:"50 anos fazendo história". O diálogo entre texto e cultura. Disponível 
<http://portalintercom.org.br/anais/nacional2015/resumos/R101435-1.pdf>. Acesso em: 8 jun. 2016.

Alexandre,C.\&Sabbatini, M. (2013). A contribuição dos Jogos Digitais nos processos de aprendizagem. Disponível em: <http://nehte.com.br/simposio/anais/Anais-Hipertexto2013/A\%20contribui\%C3\%A7\%C3\%A30\%20dos\%20Jogos\%20 Digitais\%20nos\%20processos\%20de\%20aprendizagem.pdf>. Acesso em: 17 jun. 2016.

Alves, F. (2015). Gamification: como criar experiências de aprendizagem engajadoras. São Paulo: DVS Editora.

Anastassakis, D. (2016). Sobre a utilização dos blocos de montar LEGO. Entrevista concedida ao LEAUD, por e-mail. (Inédito).

Braida, F. et al. (2015). A exploração do mundo projetual dos blocos de montar por meio do jogo digital interativo Minecraft. In: SIGraDi, 2015. Anais...São Paulo: Blucher. p. 371-377.

Brasileiros jogam mais videogame; pesquisa da Ipsos mostra que $30 \%$ da população possui consoles de games.Quem pesquisa.([s. d.]).Disponível <http://www.quempesquisa.com.br/brasileiros-jogam-maisvideogame-pesquisa-da-ipsos-mostra-que-30-da-populacaopossui-consoles-de-games/>. Acesso em: 17 jun. 2016.

Burke,B. (2015). Gamificar: como agamificaçãomotiva as pessoas a fazerem coisas extraordinárias. São Paulo: DVS Editora.

Carniello,L, Rodrigues, B \& Moraes,M. (2010). A relação entre os nativos digitais, jogos eletrônicos e aprendizagem. Disponível em: < http://nehte.com.br/simposio/anais/Anais-Hipertexto2010/Luciana-Barbosa-Carniello\&Barbara-AlcantaraGratao\&Moema-Gomes-Moraes.pdf>. Acesso em: 30 jun. 2016.

Cavazzini, M. (2014). LEGO: A história, estratégia e 15 curiosidades. Disponível em: <http://plugcitarios.com/2014/07/28/lego-historiaestrategia-e-15-curiosidades/>. Acesso em: 15 jun. 2016.

Fontenelle, R.B. (2012). LEGO completa 80 anos e continua arquitetonicamente incrível. Archdaily. Disponível em:<http://www.archdaily.com.br/78679/lego-completa-80-anose-continua-arquitetonicamente-incrivel>. Acesso em: 11 jun. 2016.
Huizinga, J. (2007). Homo ludens: o jogo como elemento da cultural. São Paulo: Perspectiva.

Mitchell, W. J. (2008). A lógica da arquitetura: projeto, computação e cognição. Campinas: Editora da UNICAMP.

Ostrower, F. (2008). Criatividade e processos de criação. 23. ed. Petrópolis: Vozes.

Quirk, V. (2014.). LEGO ${ }^{\circledR}$ e Chrome lançam Jogo Virtual LEGO (Prepare-se para procrastinar). Archdaily. Disponível em:<http://www.archdaily.com.br/173229/lego-r-e-chromelancam-jogo-virtual-lego-prepare-se-para-procrastinar>. Acesso em: 11 jun. 2016.

Rosenfield,K. (2015).Aplicativo "Lego X" de realidade aumentada promete simplificar a modelagem 3D. Archdaily. Disponível em:<http://www.archdaily.com.br/br/761444/aplicativo-lego-x-derealidade-aumentada-promete-simplificar-a-modelagem-3d>. Acesso em: 13 jun. 2016.

Rocha,M. S. P. M. L. (2009). A atividade lúdica, a criança de 6 anos e o ensino fundamental. Revista Semestral da Associação Brasileira de Psicologia Escolar e Educacional, 13(2),203-212. Disponível <http://www.scielo.br/pdf/pee/v13n2/v13n2a02.pdf>. Acessoem: 20 maio 2016.

Stiny, G.\&Gips, J. (1972). Shape grammars and the generative specification of painting and sculpture In: IFIP CONGRESS, 7. 1972, Amsterdam. Proceedingsof.... : C. V. Freimanp. 14601465. Disponível em: <http://www.shapegrammar.org/ifip/ifip1.html>. Acesso em: 1 set. 2015

Volpato,G. (2002). Jogo e brinquedo: reflexões a partir da teoria crítica. Educ. Soc., Campinas, 23(81), 217-226. Disponível em:<http://www.cedes.unicamp.br>. Acessoem: 5 fev. 2016.

The Froebel gift takes form again. (1985). The New York Times. Disponível em:<http://www.nytimes.com/1985/10/13/style/thefroebel-gift-takes-form-again.html>. Acessoem: 17 jun. 2016. 